\title{
Ebstein's Anomaly: An Impressive Cardiothoracic Ratio
}

Valdano Manuel ${ }^{1^{*}}$, Manuel Pedro Magalhães ${ }^{1}$, Humberto Morais ${ }^{2}$ and Gade Miguel ${ }^{1}$

${ }^{1}$ Cardio-Thoracic Center of Clinica Girassol, Luanda , Angola

${ }^{2}$ Cardiology Department, Hospital Militar Principal/Instituto Superior, Luanda, Angola

"Corresponding author: Valdano Manuel, Centralidade do Kilamba, X41, Apt 53, Luanda, Angola, Tel: 00244917781674; E-mail: valdanympub@gmail.com Received December 15, 2014; Accepted January 6, 2015; Published January 9, 2015

Copyright: (c) 2015 Manuel V, et al. This is an open-access article distributed under the terms of the Creative Commons Attribution License, which permits unrestricted use, distribution, and reproduction in any medium, provided the original author and source are credited

\begin{abstract}
Cardiothoracic ratio upper to 0.60 is a factor of poor prognostic in patients with Ebstein's anomaly and the prognostic is worse if is associated with others congenital heart disease. We present 4-months black boy with Ebstein's anomaly associated with atrial septal defect, pulmonary valve atresia and patent ductus arteriosus wherein the cardiothoracic ratio nearly 1.0. The patient died five hours after modified Blalock-Taussig shunt. Delay diagnosis of congenital heart disease is a big problem in developing countries and contributes for poor prognosis.
\end{abstract}

Keywords: Ebstein's anomaly; Cardiothoracic ratio; Tricuspid valve; Blalock-Taussig shunt; Chest x-ray

\section{Introduction}

Ebstein's anomaly (EA) is a rare and complex congenital heart disease (CHD) of the tricuspid valve (TV) [1]. It occurs in about 1 per 200 live births, and accounting for less than 1\% of all CHD [2-4]. EA may present at any age with a variety of hemodynamic and electrophysiologic sequel [3,4]. Clinical presentation varies from intrauterine death or neonatal heart failure until oligosymptomatic adult patients [3]. The EA can coexist with others CHD, genetic syndromes, or being associated with Wolff-Parkinson-White (WPW) syndrome [2-5]. Surgical management of EA depends of the patient age, the clinical presentation and the association with other $\mathrm{CHD}$ $[6,7]$.

The following factors have been described as predictors of death in patients with EA: echocardiographic grade 4, cardiothoracic ratio (CTR) $>60 \%$, right ventricular tract obstruction and presentation in fetal life, associated malformations, classes III-IV of the New York Heart Association, cardiac failure, cyanosis, a raised CTR, and a high mitro-tricuspid displacement indexed to body surface area $[8,9]$.

This report describe a case of a 4-months old black children with an extremely rare association of Ebstein's anomaly with atrial septal defect (ASD), pulmonary valve atresia (PVA), and patent ductus arteriosus (PDA) in whom the CTR was nearly 1.0. The authors made a brief review of predictors of poor prognostic of this anomaly.

\section{Case Report}

A 4-months old black boy presented with dyspnea and critical cyanosis. On admission at Clinica Girassol, the child was hypotonic with extremely oxygen desaturation $\left(\mathrm{SO}_{2}-25 \%\right)$ and signs of severe right heart failure. The electrocardiogram showed normal sinus rhythm, dilation of the right atrium and right bundle-branch block. The chest X-ray film showed a CTR $\geq 0.95$ (Figure 1). Transthoracic echocardiography showed apical displacement of the posterior and septal tricuspid valve leaflets with severe regurgitation and major expansion of the right atrium consistent with diagnosis of Ebstein's anomaly. ASD, PVA, and PDA were also observed.

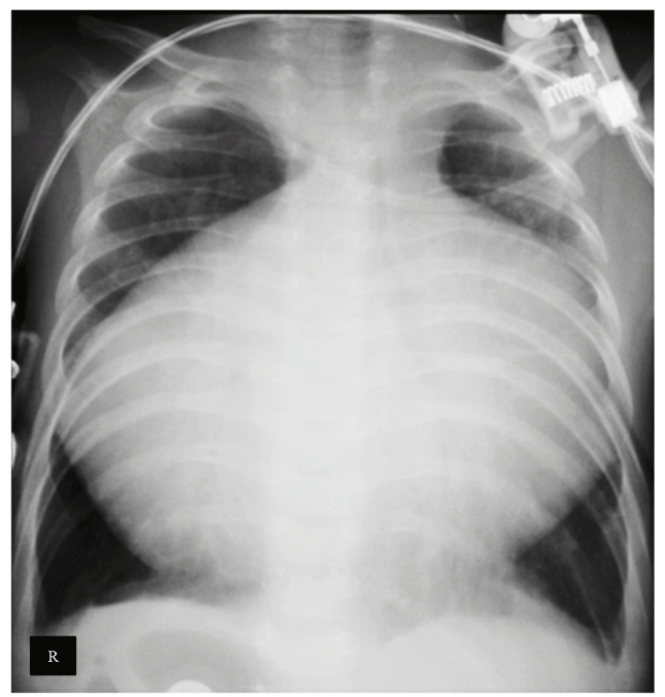

Figure 1: Chest radiograph showing cardiomegaly occupying almost all chest with cardiothoracic ratio $\geq 0.95$.

At admission we started fluids restriction, intravenous furosemide, dobutamine, and Prostaglandin E1. A modified right Blalock-Taussig (MBT) Shunt was performed at the same day, using a $4 \mathrm{~mm}$ Gore-Tex patch. Oxygen saturation $\left(\mathrm{SO}_{2}\right)$ increased up to $80-85 \%$.

In intensive care unit the patient presented the following complications atrial fibrillation, metabolic acidosis, followed by two episodes of ventricular fibrillation, cardiopulmonary resuscitation (CPR) was done without success. The patient died five hours after surgery. Autopsy was not done. 
Page 2 of 2

\section{Discussion}

Ebstein's anomaly is a rare complex congenital heart disease of the TV firstly described by Wilhelm Ebstein in 1866 [1]. It may present at any age with a variety of hemodynamic and electrophysiologic sequel [3-6]. The EA can coexist with others CHD; ASD is present in $80-94 \%$, others CHD can be present occasionally, or extremely rare as pulmonary valve atresia. The association of EA with three others CHD in the same patient is rare. Wolff-Parkinson-White (WPW) syndrome is associated up to $20 \%$ of the cases and these patients are prone to arrhythmia [3-5].

Several factors were associated with poor prognostic. Clemermajer et al. in a univariate analysis showed that a significant risk of death was associated with echocardiographic grade 4 , cardiothoracic ratio $>60 \%$, right ventricular tract obstruction and presentation in fetal life [8]. Crepin et al. found that the factors predictive of mortality were: age, associated malformations, classes III-IV of the New York Heart Association, cardiac failure, cyanosis, a raised CTR, and a high mitrotricuspid displacement indexed to body surface area [9].

The patient presented herein is a 4-months old child with dyspnea and critical cyanosis and signs of severe right heart failure in whom the echocardiogram showed a rare association of EA, ASD, PDA and pulmonary valve atresia. The chest X-ray showed a CTR $\geq 0.95$. These findings indicated that the prognostic of patient at admission was poor, and the surgical treatment was a great challenge. The patient was not suitable for total correction of the anomalies due to his condition. The oxygen saturation at admission was $25 \%$ and, the pulmonary valve atresia was interpreted as an organic lesion in echocardiogram. Patients with EA associated with right ventricular outflow tract obstruction have twice as likely to die [8]. In order to improve the patient's status he underwent a MBT shunt with great improvement of oxygen saturation. However, the evolution was unfavorable, and the patient died five hours after the surgery of malignant arrhythmia.

\section{Conclusion}

In conclusion, this case illustrated the great complexity of this anomaly and the challenge of its surgical treatment. To the best of our knowledge is the first case of Ebstein's anomaly associated with more three CHD and an impressive cardiothoracic ratio close to 1.0.

\section{References}

1. Ebstein W (1866) On a very rare case of insufficiency of the tricuspid valve caused by a severe congenital malformation of the same. Arch F Anat Physiol Wissensch Med Leipz 33: 238-254.

2. Holffman JIE, Kaplan S (2002) The Incidence of Congenital Heart Disease. J Am Coll Cardiol 1890-1900.

3. Flores Arizmendi A, Fernández Pineda L, Quero Jimenez C, Maître Azcárate MJ, Herráiz Sarachaga I, et al. (2004) The clinical profile of Ebstein's malformation as seen from the fetus to the adult in 52 patients. Cardiol Young 14: 55-63.

4. Edwards WD (1994) Embryology and pathologic features of Ebstein's anomaly. Prog Pediatr Cardiol 2: 5-15.

5. Vogel M, Marx GR, Tworetzky W, Cecchin F, Graham D, et al. (2012) Ebstein's malformation of the tricuspid valve: short-term outcomes of the "cone procedure" versus conventional surgery. Congenit Heart Dis 7: 50-58.

6. Attenhofer Jost $\mathrm{CH}$, Connolly HM, Edwards WD, Hayes D, Warnes CA, et al. (2005) Ebstein's anomaly - review of a multifaceted congenital cardiac condition. Swiss Med Wkly 135: 269-281.

7. Anderson HN, Dearani JA, Said SM, Norris MD, Pundi KN, et al. (2014) Cone reconstruction in children with ebstein anomaly: the Mayo Clinic experience. Congenit Heart Dis 9: 266-271.

8. Celermajer DS, Bull C, Till JA, Cullen S, Vassillikos VP, et al. (1994) Ebstein's anomaly: presentation and outcome from fetus to adult. J Am Coll Cardiol 23: 170-176.

9. Crepin D, Jimenez M, Thambo JB, Girardot R, Choussat A (2004) [Factors predictive of mortality in Ebstein's anomaly]. Arch Mal Coeur Vaiss 97: 535-539. 